\title{
Eritema multiforme limitado à cavidade oral em um cão: relato de caso
}

\author{
[Multiforme erythema limited to the oral cavity in a dog: case report] \\ E. Salvagni ${ }^{1}$, B.M. Lucio $^{2 *}$, R.D. Mazaro $^{2}$, C. Schmidt ${ }^{3}$, R.A. Fighera ${ }^{3}$ \\ ${ }^{1}$ Aluno de pós-graduação - Universidade Federal de Santa Maria (UFSM) - Santa Maria, RS \\ ${ }^{2}$ Aluna de graduação - Universidade Federal de Santa Maria (UFSM) - Santa Maria, RS \\ ${ }^{3}$ Universidade Federal de Santa Maria (UFSM) - Santa Maria, RS
}

\begin{abstract}
RESUMO
O eritema multiforme é uma doença incomum em cães, que afeta pele e mucosas, cuja etiologia ainda não foi completamente elucidada. Contudo, o envolvimento exclusivo da cavidade oral é considerado raro, tendo sido descrito poucas vezes até o presente momento. O objetivo deste trabalho é descrever um caso de eritema multiforme limitado à cavidade oral em um canino. Um cão, fêmea, Akita, com sete anos de idade, apresentou histórico de ulcerações na cavidade oral e nas laterais da língua, sem alterações cutâneas ou sistêmicas. O diagnóstico definitivo foi realizado por meio do exame histopatológico da mucosa oral, e a terapia imunossupressora empregada mostrou-se eficaz. Embora o eritema multiforme seja considerado incomum na espécie canina, este relato de caso apresenta a forma mais rara da doença, com poucos casos descritos em medicina veterinária.
\end{abstract}

Palavras-chave: eritema multiforme, canino, cavidade oral, estomatite, terapia imunossupressora

\begin{abstract}
Multiforme erythema is an uncommon disease in dogs that affects the skin and mucous membranes, the etiology of which has not yet been fully elucidated. However, the exclusive involvement of the oral cavity is considered rare, having been described few times until the present moment. The aim of this work is to describe a case of multiforme erythema limited to the oral cavity in a canine. A seven-year-old female dog, akita, presented a history of ulcerations in the oral cavity and on the sides of the tongue, with no cutaneous or systemic changes. The definitive diagnosis was made through the histopathological examination of the oral mисоsa and the immunosuppressive therapy used proved to be effective. Although multiforme erythema is considered uncommon in the canine species, this case report presents the rarest form of the disease, with few cases described in veterinary medicine.
\end{abstract}

Keywords: erythema multiforme, canine, oral cavity, stomatitis, immunosuppressive therapy

\section{INTRODUÇÃO}

O eritema multiforme (EM) é uma condição mucocutânea incomum, ulcerativa, bolhosa e com provável origem imunomediada. Em casos leves, geralmente é autolimitante, porém um amplo espectro de apresentações clínicas pode ser observado (Nemec et al., 2012). Em animais, essa doença já foi reconhecida em cães, gatos, equinos e bovinos (Woldemeskel et al., 2011).
Recentemente, Fisher (2013) relatou a desordem em um furão. Em cães, o EM pode ser primário (idiopático) ou secundário à administração de determinadas drogas, infecções, neoplasmas e componentes da dieta (Kersey et al., 2013).

Eritema multiforme canino é subdividido em EM maior, EM menor, necrose epidérmica tóxica (NET) e síndrome de Steven-Johnson (SSJ) (Itoh et al., 2006). Uma doença de pele branda, com

Recebido em 19 de janeiro de 2019

Aceito em 17 de outubro de 2019

*Autor para correspondência (corresponding author)

E-mail: bruna.vetcpa@gmail.com 
uma ou nenhuma mucosa afetada, é considerada eritema multiforme menor e, quando há o envolvimento de mais de uma mucosa, denominase eritema multiforme maior (Kersey et al., 2013). Formas graves da doença, envolvendo mais de $50 \%$ da superfície corporal e mais de uma mucosa, são classificadas como SSJ ou NET.

Em cães, o envolvimento da cavidade oral é descrito em $31,8 \%$ dos casos de EM. No entanto, EM restrito à cavidade oral ainda não havia sido identificado até 2012, quando Nemec et al. (2012) relataram sete casos da doença, em cães de diferentes raças, idades e sexo. Este relato descreve um caso de eritema multiforme limitado à cavidade oral em um cão. No conhecimento dos autores, esse é o segundo trabalho que descreve essa forma de apresentação do EM na espécie canina, e o primeiro no Brasil.

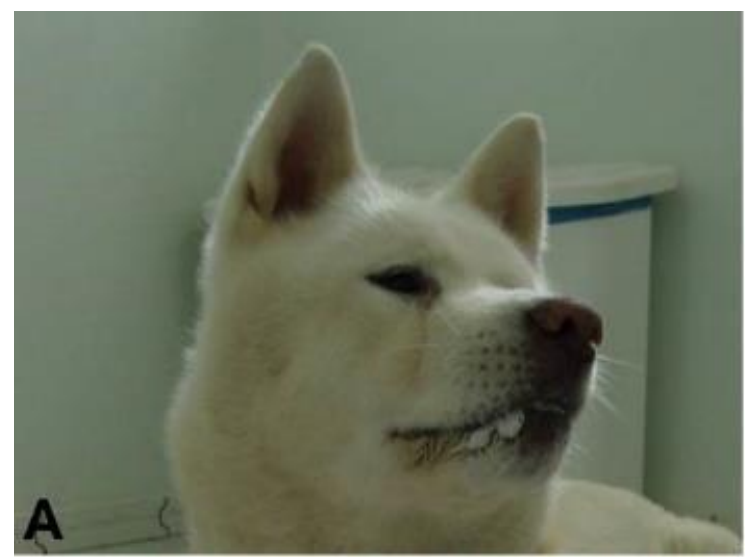

\section{CASUÍSTICA}

Um cão, fêmea, Akita, sete anos de idade, foi encaminhado para atendimento no Hospital Veterinário Universitário da Universidade Federal de Santa Maria (HVU - UFSM) apresentando histórico de lesões orais há, aproximadamente, dois anos. A paciente possuía diagnóstico prévio de candidíase oral, com cultura fúngica positiva para Candida sp. Havia recebido tratamento com fluconazol, na dose de $5 \mathrm{mg} / \mathrm{kg}$, a cada 24 horas, por via oral, durante um ano, sem resultado satisfatório. Outros medicamentos utilizados no decorrer desse período incluíam: corticosteroide, meloxicam e antibióticos (penicilina, azitromicina, doxiciclina e metronidazol). Ao exame físico, foi constatado forte halitose, odinofagia, ptialismo e múltiplas úlceras na cavidade oral e nas laterais da língua (Fig. 1).

Figura 1. Cão, Akita, fêmea, sete anos de idade, com diagnóstico de eritema multiforme limitado à cavidade oral. Observar em (A) presença de saliva nos lábios do cão (ptialismo). (B) Cavidade oral, ulceração focalmente extensa na mucosa jugal e lábios.

Não foram observadas demais alterações clínicas, hematológicas ou bioquímicas sanguíneas. Dessa forma, o animal foi submetido a procedimento cirúrgico para realização de biópsia incisional dos tecidos acometidos, considerando-se etiologias neoplásicas ou imunomediadas como principais diferenciais para as lesões. Utilizou-se um sacabocado (punch) de biópsia para coleta de amostras da mucosa oral e da língua. Os tecidos foram encaminhados para análise histopatológica ao Laboratório de Patologia Veterinária da UFSM. A terapia com fluconazol foi suspensa e foi prescrito apenas antisséptico tópico à base de clorexidina até a conclusão do laudo histopatológico.

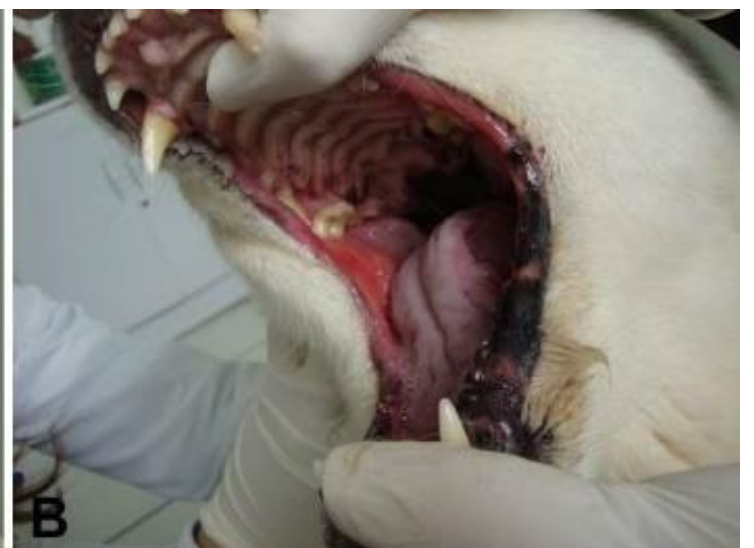

A histopatologia das amostras revelou que, na interface entre o epitélio e a lâmina própria, havia acentuado infiltrado inflamatório constituído predominantemente por plasmócitos, menor quantidade de macrófagos e linfócitos e raros neutrófilos. Havia necrose individual e aleatória de queratinócitos (apoptose), principalmente do estrato espinhoso. Essas células continham núcleos picnóticos e citoplasma fortemente eosinofílico e estavam separadas das demais por um halo claro e, frequentemente, circundadas por linfócitos, macrófagos e, raramente, neutrófilos (satelitose). Havia transmigração de macrófagos, linfócitos e neutrófilos (Fig. 2). 
Com base nos achados clínicos e histopatológicos, estabeleceu-se o diagnóstico definitivo de eritema multiforme, sendo classificado como restrito à cavidade oral, devido ao fato de o animal não apresentar outras lesões cutâneas ou mucocutâneas pelo corpo.

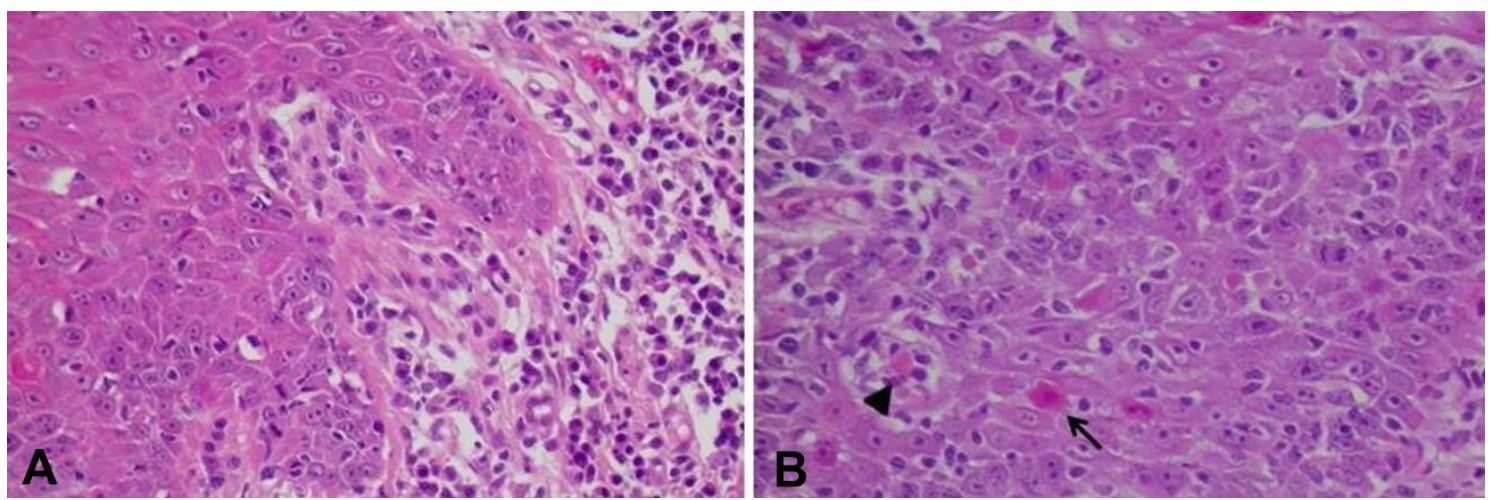

Figura 2. Histopatologia da mucosa oral do cão. Notar o infiltrado inflamatório predominantemente linfoplasmocitário na lâmina própria (A), enquanto em (B) observa-se apoptose de queratinócitos (seta) e satelitose linfocitária (cabeça de seta).

Terapia com prednisona, na dose de $2 \mathrm{mg} / \mathrm{kg}$, a cada 24 horas, por via oral, foi instituída, entretanto a resposta clínica foi leve. Após dois meses, a prednisona foi substituída por ciclosporina A, na dose de $5 \mathrm{mg} / \mathrm{kg}$, a cada 24 horas, por via oral, conforme proposto por Ferraz e Vala (2013) e Palmeiro (2013). Houve melhora significativa após 30 dias de uso desse medicamento, com notável redução na extensão das lesões e ausência de halitose, odinofagia e ptialismo. Foi recomendada a continuidade na administração da ciclosporina $\mathrm{A}$ e, conforme relato da tutora, a paciente se encontra sem alterações e mantém a terapia instituída.

\section{DISCUSSÃO}

Segundo Lommer (2013), disfagia e ptialismo, secundários à ulceração oral, podem ser a principal alteração apresentada por cães com eritema multiforme. No estudo publicado por Nemec et al. (2012), a avaliação histopatológica revelou resultados semelhantes aos descritos no presente trabalho. Esses autores concluíram que as características histológicas, isoladamente, nem sempre são conclusivas e que testes adicionais, como imuno-histoquímica e teste de clonalidade das células $\mathrm{T}$, podem ser necessários para distingui-lo do linfoma epiteliotrópico de células $\mathrm{T}$, principal diagnóstico diferencial quando apenas a mucosa oral é afetada.

EM induzido por drogas melhora acentuadamente dentro de uma a duas semanas da interrupção do medicamento agressor, enquanto EM desencadeado por antígenos necessita de terapia imunossupressora por período variável (Kang e Park, 2011).

O prognóstico para o EM varia de favorável a reservado, especialmente na impossibilidade de identificação da causa primária (Pereira et al., 2012). Quando é possível o reconhecimento da causa subjacente, e essa é eliminada, a resolução do problema ocorre por volta de três semanas, porém, em mais de $20 \%$ dos casos de EM canino, o fator que desencadeia a doença não é possível de ser identificado, razão pela qual se devem suspender todos os fármacos administrados previamente ao diagnóstico, incluindo drogas relacionadas ou com estrutura química similar (Ferraz e Vala, 2013).

Neste caso, não foi possível estabelecer o fator desencadeante do eritema multiforme do cão, entretanto acredita-se que algum fármaco utilizado previamente pelo animal possa ter incitado o desenvolvimento da enfermidade.

\section{CONCLUSÃO}

Apesar de ser considerada uma doença essencialmente dermatológica, incomum na rotina clínica veterinária, o eritema multiforme deve ser considerado como diagnóstico diferencial de cães com estomatite e/ou glossite ulcerativa, mesmo quando não houver envolvimento cutâneo. A investigação detalhada do histórico clínico do 
paciente é necessária, a fim de identificar o agente desencadeador, ainda que, na maioria das vezes, não seja possível determiná-lo. O diagnóstico definitivo é realizado por meio da histopatologia e, se a eliminação do fator desencadeante não resultar em melhora clínica, a terapia imunossupressora está indicada.

\section{REFERÊNCIAS}

FERRAZ, A.; VALA, H. Utilização de ciclosporina A - uma nova abordagem no tratamento do eritema multiforme. Vet. Med., v.33, p.11-16, 2013.

FISHER, P.G. Erythema multiforme in a ferret (Mustela putorius furo). Vet. Clin. N. Am. Exot. Anim. Pract., v.16, p.599-609, 2013.

ITOH, H.; NIBE, K.; KOJIMOTO, A. et al. Erythema multiforme possibly triggered by food substances in a dog. J. Vet. Med. Sci., v.68, p.869$871,2006$.

KANG, M.H.; PARK, H.M. Erythema multiforme minor in a dog following inappropriate intranasal Bordetella bronchiseptica vaccination: a case report. Vet. Med., v.56, p.568-572, 2011.
KERSEY, M.K.; ROSALES, M.; ROBERTS, B.K. Dermatologic emergencies: identification and treatment. Compend. Contin. Educ. Vet., v.35, p.e1-e9, 2013.

LOMMER, M.J. Oral inflammation in small animals. Vet. Clin. N. Am. Small Anim. Pract., v.4, p.555-571, 2013.

NEMEC, A.; ZAVODOVSKAYA, R.; AFFOLTER, V.K.; VERSTRAETE, F.J. Erythema multiforme and epitheliotropic T-cell lymphoma in the oral cavity of dogs: 1989 to 2009. J. Small Anim. Pract., v.53, p.445-452, 2012.

PALMEIRO, B.S. Cyclosporine in veterinary dermatology. Vet. Clin. N. Am. Small Anim. Pract., v.43, p.153-171, 2013.

PEREIRA, D.T.; SCHMIDT, C.; HARTMANN, H.F. et al. Eritema multiforme em cão. Medvep Dermatol., v.2, p.86-92, 2012.

WOLDEMESKEL, M.; LIGGETT, A.; ILHA, M. et al. Canine parvovirus - $2 \mathrm{~b}$ - associated erythema multiforme in a litter of English Setter dogs. J. Vet. Diagn. Invest., v.23, p.576-580, 2011. 